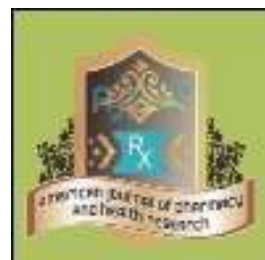

Research Article AMERICAN JOURNAL OF PHARMACY AND HEALTH RESEARCH www.ajphr.com 2020, Volume 8, Issue 3 ISSN: 2321-3647(online)

\title{
A Comparative Study to Evaluate the Risk Of Metabolic Syndrome In Premenopausal and Postmenopausal Women
}

\author{
Khushbu Jasotani, Jairam Rawatani, \\ Dr. SN Medical College, Jodhpur
}

\begin{abstract}
The menopausal state is itself noted to be an independent risk factor for the occurrence of metabolic syndrome. This study was conducted to find the prevalence of metabolic syndrome in postmenopausal women. It was an Observational study. Total 100 females were enrolled, 50 premenopausal(Group I) and 50 menopausal (Group II) were included in the study. There was a statistic significant increase in serum glucose, serum total cholesterol (TC), triglycerides (TG), LDL-cholesterol, VLDL-cholesterol levels, insulin, insulin resistance in post-menopausal women. HDL-cholesterol level and estradiol concentration was significantly lower in postmenopausal women. Menopause leads to changes in blood glucose, serum insulin, lipid profile by reducing HDL, and elevating total cholesterol (TC), triglycerides (TG), LDL-cholesterol and VLDL-cholesterol, thus increasing the risk for cardiovascular disease. These changes are caused by reduced estrogen concentrations which are seen in menopause.
\end{abstract}

Keywords: Menopause, metabolic syndrome, postmenopausal women, cardio vascular disease. 


\section{INTRODUCTION}

Menopause is the permanent cessation of menstruation resulting from the loss of follicular activity. It is a natural biological event, not a disease or illness and is recognized by the presence of amenorrhea for 12 consecutive months without any pathological and physiological factors. ${ }^{1}$

The metabolic syndrome (MS) (syndrome X or insulin resistance syndrome) is a constellation of metabolic abnormalities and a complex pre disease state that predicts future development of type 2 diabetes mellitus and cardio vascular disease. ${ }^{2}$

According to National Cholesterol Education Program's Adult Treatment Panel III report (NCEP, ATP III), there are six components of the metabolic syndrome identified which include, a)Abdominal obesity, b) Atherogenic dyslipidemia, c)Raised blood pressure, d)Insulin resistance \pm glucose intolerance, e)Pro inflammatory state, f)Pro thrombotic state..$^{3,4}$

The prevalence of MS is influenced by genetic background, age, sex, diet, and levels of physical activity. ${ }^{5}$ There is observed increase in the prevalence of MS in India, and other South Asian countries and the main drivers to this are lifestyle and socioeconomic transitions consequent to increased affluence, urbanization, and mechanization and rural to urban migration. ${ }^{6}$

Menopausal transition and postmenopausal state are considered as a vulnerable period for developing Metabolic syndrome, and this increased risk has been attributed to decreasing estrogen levels with an increasing risk of insulin resistance following menopause. ${ }^{7,8}$ The Metabolic syndrome in postmenopausal women, in particular, needs to be given adequate attention as early as possible followed by an aggressive approach toward prevention and management. ${ }^{9}$

In India, prevalence of metabolic syndrome amongst postmenopausal women is significantly higher than that in premenopausal women as per the studies by International Diabetes Federation (pre menopausal 45\% and postmenopausal 55\%) and Harmonization criteria (premenopausal $44 \%$ and postmenopausal $56 \%){ }^{10}$

\section{MATERIALS AND METHOD}

The present study was conducted on 50 pre menopausal healthy female subjects of varying age and 50 post menopausal female subjects attending the Out Patient Clinic of Dr. S.N. Medical College and its Associated Group of Hospitals, Jodhpur. All the investigation work was performed in the clinical laboratory of Department of Biochemistry, Dr. S.N. Medical College Jodhpur.

\section{Study Groups:}

The subjects were grouped as:- 
Group 1: 50 Pre menopausal healthy female subjects of age varying from 18-45 years.

Group 2: 50 Post menopausal female subjects who had attained their menopause, with age varying from 49 to 68 years.

\section{Inclusion criteria-}

\section{For Pre menopause Women:}

Pre menopausal healthy women having no history of obesity and no known medical condition.

\section{For Post menopausal Subjects:}

Post menopausal women who had attained their menopause (at least one year back).

\section{Exclusion criteria-}

- Subjects found to have any known medical condition such as thyroid disorder, cardiovascular disease and type 2 diabetes mellitus.

- Subjects on hormone replacement therapy (HRT) or lipid lowering drugs.

- Subjects had undergone prior any form of Surgery especially of reproductive organs, liver and pancreas.

- Subjects who are smokers and alcoholics.

An ethical clearance was obtained from the ethical committee of Dr.S.N. Medical College, Jodhpur.

Anthropometric indices like height, weight, BMI, waist circumference, hip circumference and WHR were recorded. Waist circumference was measured at a level midway between the bottom rib cage and superior margin of iliac crest. The hip circumference was measured at the maximal diameter of buttock. Blood pressure was recorded using a sphygmomanometer in sitting posture. After an overnight fast of 10-12 hours, venous blood sample was drawn from anticubital vein of each subject by using standard aseptic techniques. Plasma glucose was measured by End point Enzymatic Glucose Oxidase and Peroxidase (GOD-POD) method. Serum insulin was measured by Solid Phase Enzyme Linked Immunosorbent Assay Method. Insulin Resistance was calculated with Homeostatic model assessment of Insulin resistance (HOMA-IR).Lipid profile was measured by End point enzymatic method and Friedwalds formula. Serum Estradiol was measured by Enzyme Linked Fluorescent Assay Method.

\section{Statistical analysis}

The data assembled for different anthropometric and biochemical parameters were subjected to suitable statistical analysis to compute central tendencies (mean) and accompanying measures of variability statistics (standard deviation) for all the groups. The magnitude of inter group differences for each of the parameters was quantified by using student's compute ' $t$ ' test values 
(Student's ' $t$ ' test). On the basis of t-values, 'p' values (probability) were determined to find out significance of variance between the mean values of individual parameters among the groups of subjects studied. ${ }^{11}$

\section{RESULTS AND DISCUSSION}

The present study was undertaken to look for metabolic syndrome in premenopausal and postmenopausal females. 100 female subjects attending the medical OPD were included in the study and then evaluated for metabolic syndrome using NCEP, ATP(III) criteria. Age of women ranged from 18 to 68 years. Mean age of women in Group I (premenopausal) was $29.34 \pm 7.61$ years and mean age of women in Group II (postmenopausal) was $62.14 \pm 9.75$ years.

Metabolic syndrome was more prevalent among Group II (postmenopausal) than Group I (premenopausal).

Among the anthropometric parameters, mean body weight, body mass index, Waist hip ratio of Group II women were significantly higher as compared to that of Group I, while among the cardiovascular parameters, Mean systolic blood pressure (SBP) and diastolic blood pressure (DBP) also significantly higher in Group II as compared to that of Group I, as shown in table 1.

Table 1: Anthropometric Parameters of Both Groups

\begin{tabular}{lllll}
\hline Variables & $\begin{array}{l}\text { Group I } \\
\text { Mean } \pm \text { SD }\end{array}$ & $\begin{array}{l}\text { Group II } \\
\text { Mean } \pm \text { SD }\end{array}$ & t- value & p-value \\
\hline Body weight(kgs) & $54.74 \pm 3.71$ & $62.8 \pm 3.63$ & 10.98 & $<0.0001(\mathbf{H S})$ \\
BMI $\left(\mathrm{kg} / \mathrm{m}^{2}\right)$ & $22.62 \pm 1.26$ & $27.77 \pm 1.43$ & 16.78 & $<0.0001(\mathbf{H S})$ \\
Waist Circumference $(\mathrm{cm})$ & $84.14 \pm 2.61$ & $92.92 \pm 2.13$ & 18.91 & $<0.0001(\mathbf{H S})$ \\
Hip Circumference $(\mathrm{cm})$ & $91.54 \pm 6.85$ & $94.46 \pm 6.62$ & 2.16 & $<0.03(\mathbf{S})$ \\
Mean Waist hip ratio & $0.91 \pm 0.07$ & $0.98 \pm 0.06$ & 5.36 & $<0.001(\mathbf{H S})$ \\
Systolic Blood Pressure $(\mathrm{mm} \mathrm{Hg})$ & $126.24 \pm 6.52$ & $135.32 \pm 7.25$ & 6.58 & $<0.0001(\mathbf{H S})$ \\
Diastolic Blood Pressure $(\mathrm{mm} \mathrm{Hg})$ & $83.44 \pm 5.25$ & $86.72 \pm 6.07$ & 2.88 & $<0.004(\mathbf{H S})$ \\
\hline
\end{tabular}

HS-Highly Significant, S-Significant

Among the biochemical parameters, Mean Fasting Blood Sugar (FBS), Serum Insulin level, Insulin Resistance(HOMA-IR), Total Cholesterol (TC), Triglycerides, VLDL-c, LDL-c levels were higher in Group II as compared to Group I. Mean HDL-c and estradiol level were lower in Group II as compared to Group I which was significant statistically as shown in table 2.

Table 2: Biochemical Parameters of Both Groups

\begin{tabular}{lllll}
\hline Variables & $\begin{array}{l}\text { Group I } \\
\text { Mean } \pm \text { SD }\end{array}$ & $\begin{array}{l}\text { Group II } \\
\text { Mean } \pm \text { SD }\end{array}$ & t- value & p-value \\
\hline Fasting Blood Glucose $(\mathrm{mg} / \mathrm{dl})$ & $86.04 \pm 13.10$ & $104.90 \pm 12.42$ & 7.38 & $<0.0001(\mathbf{H S})$ \\
Fasting Serum Insulin $(\mu \mathrm{IU} / \mathrm{ml})$ & $10.90 \pm 1.57$ & $24.11 \pm 3.87$ & 22.36 & $<0.0001(\mathbf{H S})$ \\
HOMA-IR & $2.37 \pm 0.63$ & $6.53 \pm 1.80$ & 15.42 & $<0.0001(\mathbf{H S})$ \\
Total Cholesterol $(\mathrm{mg} / \mathrm{dl})$ & $165.84 \pm 19.89$ & $225.00 \pm 35.52$ & 10.27 & $<0.0001(\mathbf{H S})$ \\
\hline
\end{tabular}




\begin{tabular}{lllll}
\hline Triglycerides $(\mathrm{mg} / \mathrm{dl})$ & $103.82 \pm 20.66$ & $152.54 \pm 54.72$ & 5.88 & $<0.0001(\mathbf{H S})$ \\
HDL-c $(\mathrm{mg} / \mathrm{dl})$ & $44.7 \pm 3.73$ & $41.6 \pm 7.19$ & 2.70 & $<0.008($ HS $)$ \\
VLDL-c(mg/dl) & $20.68 \pm 4.16$ & $30.50 \pm 10.94$ & 5.93 & $<0.008($ HS $)$ \\
LDL-c $(\mathrm{mg} / \mathrm{dl})$ & $100.41 \pm 16.47$ & $152.85 \pm 35.57$ & 9.45 & $<0.0001($ HS $)$ \\
Estradiol $(\mathrm{pg} / \mathrm{ml})$ & $256.70 \pm 69.68$ & $43.53 \pm 15.39$ & 22.17 & $<0.001($ HS $)$ \\
\hline
\end{tabular}

HS-Highly Significant, S-Significant

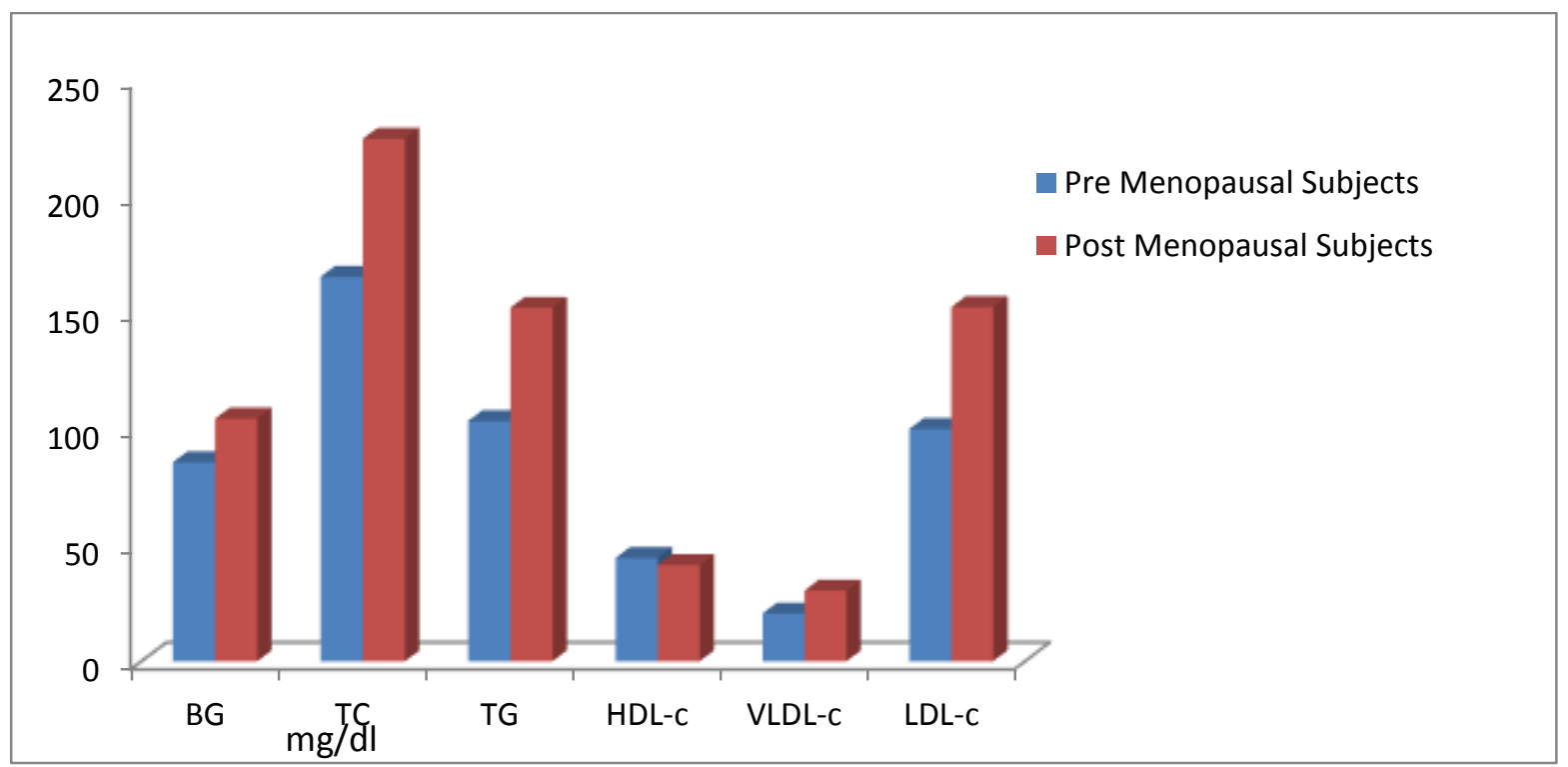

Figure 1: Comparison of Blood Glucose and Lipid Profile

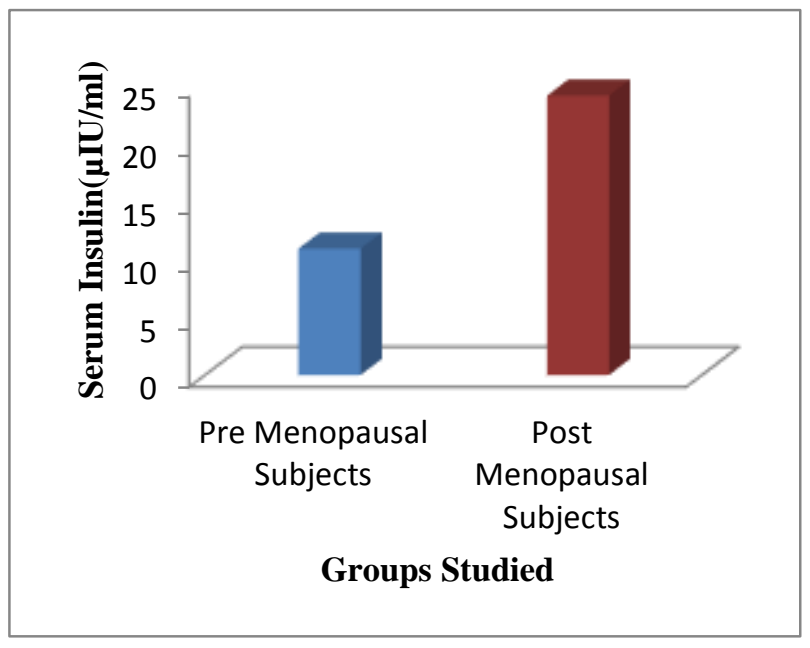

Figure 2: Comparison of Serum Insulin

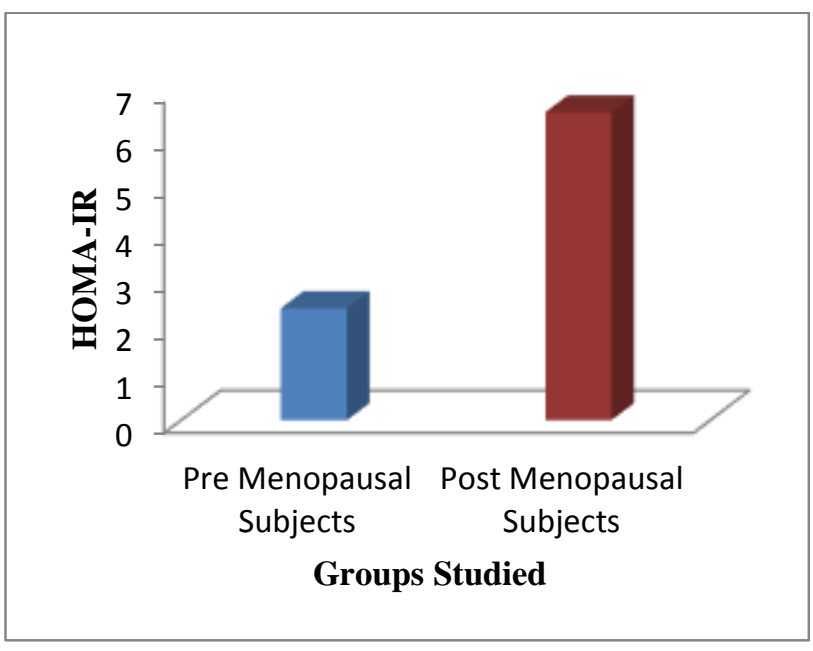

Figure 3: Comparison of HOMA-IR 


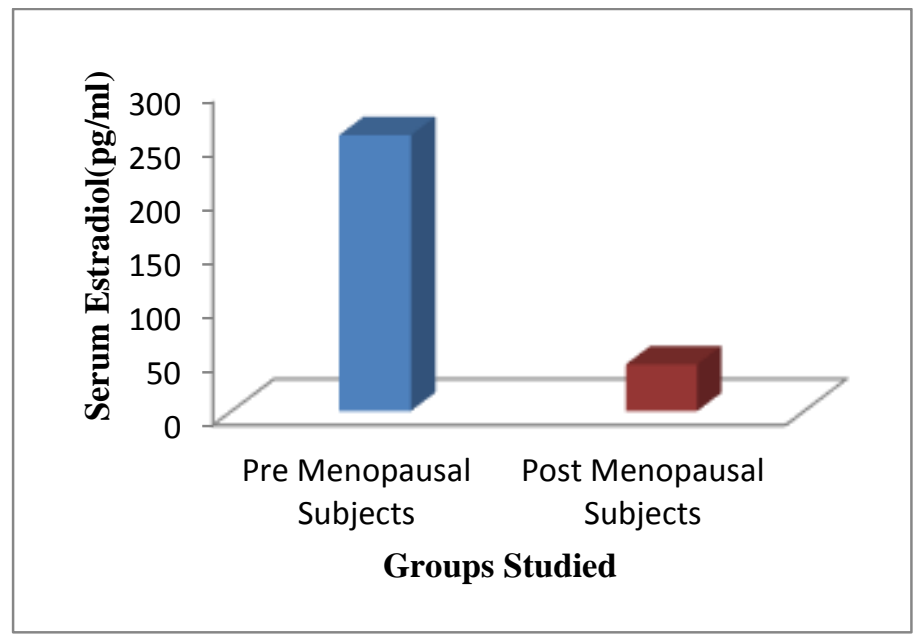

Figure 4: Comparison of Serum Estradiol

\section{DISCUSSION}

Menopause is a natural aging process causing estrogen deficiency as the ovaries become less functional. In premenopausal period, women have a significantly lower risk for cardiovascular disease compared to post menopausal women. After menopause, the reduced estrogen production from ovaries results in derangement of lipoprotein profile, adverse changes in glucose and insulin metabolism, body fat distribution, coagulation and fibrinolysis and dysfunction of vascular endothelium. ${ }^{12,13}$ Estrogens have several cardio-protective mechanisms that change the vascular tone by increasing nitrous oxide production. Estrogens stabilize the endothelial cells, they enhance antioxidant effects and alter fibrinolytic protein. All these are cardio protective mechanisms which get lost with the onset of menopause. ${ }^{14,15}$ As plasma lipids can be divided into the proatherogenic lipoproteins and antiatherogenic HDL. ${ }^{16}$ A lower atherogenic index in premenopausal women indicates a greater proportion of HDL-C, and it thus satisfies the criteria for a reduced risk of coronary heart disease. ${ }^{17}$ Postmenopausal women in our study had lower HDL concentrations, which was confirmed by many studies, although studies that contradict these findings also exist.

Numerous Studies have demonstrated that high levels of HDL-C are associated with a lower incidence of CHD. Conversely, low levels of HDL-C are associated with a higher incidence of CHD. The protective mechanism which involves HDL may be due to its role in reverse cholesterol transport, which results in redistribution of cholesterol away from the artery wall and by inhibition of monocyte adhesion and antioxidative activities, that could prevent LDL oxidation. 
The LDL oxidation results in lipid peroxidation. Lipid peroxidation may be a component of the general aging process. Oxidized LDLs increase macrophage uptake, they are cytotoxic, they serve as chemoattractants for circulating monocyte-macrophages, and are immunogenic.

Menopause leads to changes in lipid profile by reducing HDL, and elevating Total Cholesterol (TC), triglycerides (TG), LDL-cholesterol and VLDL-cholesterol, thus increasing the risk for cardiovascular disease. The results of this study were in agreement with those of earlier studies, which suggested that changes in lipid profile were caused by reduced oestrogen concentrations which were seen in menopause.

Estrogen may regulate insulin action directly via actions on insulin-sensitive tissues or indirectly by regulating factors like oxidative stress, which contribute to insulin resistance. Estrogen may also mediate its protective effects on insulin action via reduction of inflammation. ${ }^{18}$

In our study, Prevalence of metabolic syndrome in postmenopausal women is $82 \%$. Such a high prevalence of metabolic syndrome in postmenopausal group is an alarming sign. Prevention through changes in lifestyle, control of obesity, early detection and treatment of elevated fasting blood glucose, hypertension, hyperlipidemia, insulin resistance and pro inflammatory state are necessary for prevention of cardiovascular diseases in women reaching menopause which may result in lower cardiovascular events and can give a good quality of life to post menopausal women.

Further Health professionals should consider the postmenopausal women as a major target group for prevention of metabolic syndrome, which is an underlying condition of many noncommunicable diseases and should run educational programs to improve women's knowledge about a healthy lifestyle.

\section{ACKNOWLEDGEMENTS}

The authors would like to thank all the participants who took part in the study.

\section{REFERENCES}

1. Yeasmin N, Akhter QS, Mahmuda S, Banu N, Yeasmin S, Akhter S, Nahar S. Association of Hypertension with Serum Estrogen Level in Postmenopausal Women. Mymensingh medical journal: MMJ. 2017 Jul;26(3):635-41.

2. Longo DL, Kasper DL, Jameson JL, Fauci AS, Hauser SL, Loscalzo J. Harrison's Principles of Internal Medicine. 18th ed. New York: The McGraw-Hill Companies; 2012.

3. Misra A, Athiko D, Sharma R, Pandey RM, Khanna N. Non-obese hyperlipidemic Asian northern Indian males have adverse anthropometric profile. Nutrition, metabolism, and cardiovascular diseases: NMCD.2002 Aug;12(4):178-83. 
4. Fang ZY, Prins JB, Marwick TH. Diabetic cardiomyopathy: evidence, mechanisms, and therapeutic implications. Endocrine reviews. 2004 Aug 1;25(4):543-67.

5. De Ferranti SD. Recovery from metabolic syndrome is both possible and beneficial. ClinChem 2010;56:1053-55.

6. Shah D. The annual conference of the British menopause society-June 2010. Journal of mid-life health. 2010 Jan;1(1):48-50.

7. Rajewska J, Rybakowski JK. Depression in premenopausal women: gonadal hormones and serotonergic system assessed by D-fenfluramine challenge test. Progress in NeuroPsychopharmacology and Biological Psychiatry. 2003 Jun 1;27(4):705-9.

8. Carrasco GA. Van de Kar. Neuroendocrine pharmacology of stress. Eur J Pharmacol. 2003;463:235-72.

9. Gupta R, Sarna M, Thanvi J, Rastogi P, Kaul V, Gupta VP. High prevalence of multiple coronary risk factors in Punjabi Bhatia community: Jaipur Heart Watch-3. Indian heart journal. 2004;56(6):646-52.

10. Pandey S, Srinivas M, Agashe S, Joshi J, Galvankar P, Prakasam CP, Vaidya R. Menopause and metabolic syndrome: A study of 498 urban women from western India. Journal of mid-life health. $2010 \mathrm{Jul} ; 1(2): 63$.

11. Mahajan BK, Lal S. Methods in biostatistics for medical students and research workers. Indian Journal of Community Medicine. 1999 Jul 1;24(03):140.

12. Bales AC. In search of lipid balance in older women; New studies raise questions about what works best. Postgrad. Med. 2000;108 (7): 57-72.

13. Spencer CP, Godsland H, Stevenson JC. Is there a menopausal metabolic syndrome? Gynecol. Endocrinol. 1977; 11: 341-55.

14. Taddec S, Virdis A, Ghiadoni L, Mattec P, Sudano I, Bernini G. Menopause is associated with endothelial dysfunction in women. Hypertension. 1996;.28: 576- 82.

15. JC Igweh et al, The effects of menopause on the serum lipid profile of normal females of south east Nigeria. Nigerian Journal of Physiological Sciences. 2005; 20 (1-2): 48-53.

16. The Expert Panel : Third Report of the National Cholesterol Education Program (NCEP) Expert Panel on Detection, Evaluation, and Treatment of High Blood Cholesterol in Adults (Adult Treatment Panel III). Final report. Circulation. 2002; 106:3143-421.

17. Grady D, SM Robin, DB Petitti, CS Fox, D. Black- Expert Panel,. Report of the National Cholesterol education programme. Expert panel on detection and evaluation and treatment of high blood cholesterol in adults. Arch. Int. Med., 1993;148: 36-69. 
18. Hewitt SC, Korach KS. Estrogen receptors: structure, mechanisms and function. Reviews in Endocrine and Metabolic Disorders. 2002 Sep 1;3(3):193-200.

AJPHR is

Peer-reviewed

monthly

Rapid publication

Submit your next manuscript at

editor@ajphr.com / editor.ajphr@gmail.com 